\title{
Cortical potentials evoked by confirming and disconfirming feedback following an auditory discrimination*
}

\author{
KENNETH C. SQUIRES \\ Department of Psychology, University of California, San Diego, La Jolla, California 92037 \\ STEVEN A. HILLY YARD \\ Department of Neurosciences, University of Califomia, San Diego, La Jolla, Califormia 92037 \\ and \\ PETER H. LINDSAY \\ Department of Psychology. University of California, San Diego, La Jolla, California 92037
}

\begin{abstract}
Vertex potentials elicited by visual feedback signals following an auditory intensity discrimination have been studied with eight Ss. Feedback signals which confirmed the prior sensory decision elicited small P3s, while disconfirming feedback elicited P3s that were larger. On the average, the latency of P3 was also found to increase with increasing disparity between the judgment and the feedback information. These effects were part of an overall dichotomy in waveshape following confirming vs disconfirming feedback. These findings are incorporated in a general model of the role of $\mathrm{P} 3$ in perceptual decision making.
\end{abstract}

The unique sensitivity of the late-positive wave of the cortical evoked potential (latency $300-400 \mathrm{msec}$ ) to the information conveyed by the sensory event was first described by Sutton, Braren, Zubin, and John (1965). Since then the selective enhancement of this "P300" or "P3" component has been demonstrated in a variety of perceptual decision-making tasks. The necessary (but not sufficient) conditions for enhancing the $\mathrm{P} 3$ wave seem to be twofold: first. attention must be paid to signals that are relevant to the current task. and second, there must be uncertainty in some aspect of the signal scheduling: completely predictable events do not elicit large P3s. even when highly relevant.

Those signals which evoke large $\mathrm{P} 3 \mathrm{~s}$ can be characterized as delivering the information being sought. thereby "resolving" prior uncertainty (Sutton, Tueting. Zubin, \& John, 1967). Accordingly, an enhanced P3 is seen to follow: (1) a signal which confirms or disconfirms a prior guess (Sutton et al, 1965: Tueting. Sutton, \& Zubin, 1971), (2) solution of an auditory intensity discrimination (Sutton et al. 1967: Ritter \& Vaughan, 1969: Hirsh, 1971: Sheatz \& Chapman, 1969). (3) the detection of a threshold-level auditory signal (Hillyard, Squires, Bauer, \& Lindsay, 1971; Paul \& Sutton. 1972: Squires, Hillyard. \& Lindsay ${ }^{1}$ ). (4) a signal for a simple or choice reaction (Wilkinson \& Morlock. 1967: Donchin \& Smith, 1970: Karlin, Martz. Brauth, \& Mordkoff, 1971), (5) an occasional stimulus change (Ritter, Vaughan. \& Costa, 1968; Klinke, Fruhstorfer. \& Finkenzeller. 1968: Smith, Donchin.
Cohen, \& Starr, 1970; Picton, Hillyard. \& Galambos, 1972), (6) a signal to shift sensory-motor set (Donald \& Goff, 1971), and (7) a letter which completes a word (Shelbourne, 1972).

Several general formulations of the psychological processes which accompany $\mathrm{P} 3$ have been offered. Ritter and Vaughan (1969), taking into account evidence that a large P3 follows an unexpected omission or change in a repetitive stimulus, proposed that $\mathrm{P} 3$ indexes the reaction of orientation and cognitive evaluation. Smith et al (1970) have regarded the P3 as the concomitant of "a decision regarding the stimulus." presumably the sequel of an evaluation. Sutton (1970) has emphasized the sensitivity of $\mathrm{P} 3$ as a measure of the subjective significance of a signal and offered the term "salience" as tentative psychological correlate. Finally, Karlin (1970) linked the evocation of P3 to a "reactive change of state" from high to lower arousal.

The present study investigated the $\mathbf{P} 3$ in a paradigm wherein a feedback signal informs the $S$ whether his perceptual judgment was correct or incorrect Nielson. Teas. \& Idzikowski, 1970: Jenness. 1971: Picton \& Low. 1971: Benson \& Teas. 1972). In a prior study. which compared P3s evoked by confirming and disconfirming feedback (in a random guessing paradigm). Tueting et al (1971) reported no overall difference that could be dissociated from outcome probabilities. In the present paradigm, however. the content of the feedback information was found to influence $\mathrm{P} 3$ in a manner not wholly dependent upon signal probability.

*This research is supported by NIH Grant NS 07454 and NASA Grant NGR-05-009-83. We thank Dr. Donald Norman fo providing the experimental facilities.

\section{METHOD}

Evoked potentials elicited b! visual feedback signals following 
Table 1

The Joint Probability and Contingent Probability of Occurrence of Each Type of Trial*

\begin{tabular}{|c|c|c|c|c|}
\hline \multirow{2}{*}{$\begin{array}{l}\text { Confi- } \\
\text { dence } \\
\text { Rating }\end{array}$} & \multicolumn{2}{|c|}{$\begin{array}{l}\text { Joint Probability of } \\
\text { Each Type of Trial }\end{array}$} & \multirow{2}{*}{$\begin{array}{c}\text { Contingent } \\
\text { Probability } \\
\text { of Red } \\
\text { Light } \\
\text { Given } \\
\text { Rating }\end{array}$} & \multirow{2}{*}{$\begin{array}{c}\text { Contingent } \\
\text { Probability } \\
\text { of Being } \\
\text { Correct } \\
\text { Given } \\
\text { Rating }\end{array}$} \\
\hline & $\begin{array}{l}\text { Red } \\
\text { Lig̣ht }\end{array}$ & $\begin{array}{l}\text { Green } \\
\text { Light }\end{array}$ & & \\
\hline 1 & 0.13 & 0.02 & 0.88 & 0.88 \\
\hline 2 & 0.11 & 0.04 & 0.72 & 0.72 \\
\hline 3 & 0.16 & 0.08 & 0.53 & 0.53 \\
\hline 4 & 0.05 & 0.08 & 0.36 & 0.64 \\
\hline 5 & 0.04 & 0.11 & 0.26 & 0.74 \\
\hline 6 & 0.03 & 0.21 & 0.14 & 0.86 \\
\hline
\end{tabular}

*Distributions aleraged orer eight Ss.

an auditory intensity discrimination were recorded from eight Ss. including Es K.S. and S.H. The S's task was to decide whether the more or less intense of two just discriminable $1.000-\mathrm{Hz} 50$-msec signals was presented on each trial and to rate his confidence (on a 3 -point scale) in that decision. The lower intensity signal was set at $46 \mathrm{~dB}$ SPL. and the higher intensity signal was adjusted to $1-3 \mathrm{~dB}$ greater. according to $\mathrm{S}$, to achieve $75 \%$ correct performance.

During testing. the $S$ sat in an acoustically shielded chamber wearing TDH-39 earphones and fixating his gaze on a 2-deg yellow neon bulb. Each trial began with a $200-\mathrm{msec}$ flash of this bulb. followed $500 \mathrm{msec}$ later by a signal presented binaurally against a continuous background of wide-band white noise $170 \mathrm{~dB}$ SPL). The yellow bulb was illuminated again (response light) $1.5 \mathrm{sec}$ after the signal. thereby directing the $S$ to respond by pressing one of six numbered buttons. When highly confident that the higher intensity signal had been presented, he pressed Button 1: $a$ " 3 " indicated marginal confidence that the higher intensity signal had been presented: a " 4 " indicated marginal confidence that the lower intensity had been presented: and a " 6 " indicated high confidence that the lower intensity signal had been presented.

A feedback light. situated 5 deg to the right of the fixation light. was illuminated starting $1.000 \mathrm{msec}$ after the buttonpress and remained on for $750 \mathrm{msec}$. A 2 -deg red bulb signified that the higher intensity signal had been presented, and an adjacent I-deg green bulb indicated that the lower intensity signal had been presented. Intertrial intervals were randomized. ranging from 3 to $4 \mathrm{sec}$.

Each S Ias given enough experience (200-500 trials) in the task to stabilize his distribution of judgments before evoked potential recording was begun. Trials were presented in blocks of 70. with 4 or 5 blocks per 2 -h testing session. Each $S$ participated in from three to seven sessions.

Eroked potentials were recorded from the vertex referred to the right mastoid. using $\mathrm{Ag}-\mathrm{AgCl}$ electrodes (Beckman), and amplified with Grass P-15 amplifiers (bandpass $0.1-300 \mathrm{~Hz}$ ). Only potentials evoked during the $750-\mathrm{msec}$ feedback interval are presented in this report. The evoked potentials were averaged according to the 12 combinations formed by six numerical response categories and two feedback signals. Additional recordings were taken in a "passive" control condition, wherein the S simply fixated on the vellow light while the feedback lights were flashed in random order every $4-6 \mathrm{sec}$.

Possible artifacts due to eve movements were eliminated either by monitoring the vertical EOG and automatically rejecting trials in which the peak-to-peak EOG exceeded $30 \mu \mathrm{V}$ or by averaging the LOG and retaining only blocks of data in which there was no evidence of eve movements. In order to ensure that differential lateral eve movements toward the feedback lights were not responsibie for the evoked potential effects. two alternative modes of feedback presentation were also tested. Visual feedback signals in the form of $1 / 2$-deg letter: presented at a constant location on an oscilloscope face for $200 \mathrm{msec}$ duration were used with Ss N.H. and K.S.. and auditory feedback consisting of $200-\mathrm{msec}$ tones was used with K.S. Results equivalent to those for the red and green feedback lights were obtained in both cases.

Stimulus timing. signal presentation. and evoked response collection was under the control of a PDP-9 computer. Measurements of evoked potential waveform parameters and statistical analysis of these data were also performed with this computer.

\section{RESULTS}

The red feedback light informed the $S$ that the "loud" signal had been presented, making Responses 1, 2. and 3 correct and Responses 4, 5 , and 6 incorrect: conversely. the green light gave confirming feedback for Responses 4, 5, and 6 and disconfirming feedback for Responses 1 , 2. and 3. The proportion of trials of each ty pe, i.e.. the joint probability of occurrence, is given in the first two columns of Table 1. The proportion of trials of a given confidence rating that were followed by a red feedback light, i.e., the contingent probability of occurrence. is shown in the third column to increase with increasing confidence that the higher intensity signal had been presented. The orderly relation between the confidence ratings and the contingent probability of being correct is shown in the far right column of Table 1 .

Vertex evoked potentials averaged separately for each combination of judgment feedback are shown in Fig. 1 for N.S. The early evoked potential components, a small negative wave at about $160 \mathrm{msec}$, and a sharp positive peak at about $240 \mathrm{msec}$ were relatively invariant on all types of trials, including those of the passive (control) condition. When confirming feedback was delivered. a broad positive deflection was added to these early components throughout the range of $260-450 \mathrm{msec}$, peaking at about $320 \mathrm{msec}$. On the other hand. when the light informed the $S$ that his decision had been incorrect, the late positive "P3" wave was sharply accentuated into a well-defined peak that was delayed in latency to $360-400 \mathrm{msec}$. K.S. (Fig. 2) displayed similar results: a broad positive deflection occurred following confirming feedback. and a more pronounced $\mathrm{P} 3$ of longer peak latency occurred following disconfirming feedback. This dichotomy of waveshape was similarly pronounced for the remaining six Ss, all of whom had consistently larger P3 waves following disconfirming feedback.

The magnitude of $\mathrm{P} 3$ (measured as the net area within the interval between 300 and $350 \mathrm{msec}$ post signal onset relative to a baseline of the initial $60 \mathrm{msec}$ of the feedback interval) is presented for all Ss in Table 2 as a function of the degree to which the feedback confinms or disconfirms the perceptual decision. The P3 areas for the red and green feedback lights are combined. since the two lights deliver equivalent information and since an analysis of variance showed they did not diffe: 
significantly. For example, the P3 area for a red light following a correct, highly confident " 1 ". response was combined with that for a correct, highly confident " 6 " response and a green light. The P3 area for disconfirming feedback is, on the average, $70 \%$ larger than for confirming feedback. For no $S$ is there an instance where a P3 for confirming feedback is as large as those for disconfirming feedback. The results averaged over all Ss are plotted in Fig. 3, after converting each P3 area to a proportion of the maximum area obtained for that $S$. In this figure, the abscissa represents an ordering of the disparity between the judgment and the feedback. While the overall linear increasing trend of $\mathrm{P} 3$ area as a function of increasing discrepancy between rating and feedback is highly significant $(p<.0001)$, the linear trends within the confirming and disconfirming groups were not. The only significant change in $\mathrm{P} 3$ area between successive ratings occurred at the boundary between confirming and disconfirming feedback [i.e., between Ratings 3 and $4(\mathrm{p}<.005)$ ], indicating a discontinuity in this $\mathrm{P} 3$ area function.

From Table 1, it is evident that the increase in the size of $\mathrm{P} 3$ is also correlated with a decreasing probability of occurrence. In other words, the more disconfirming feedback, which evokes larger P3s, was also less likely to

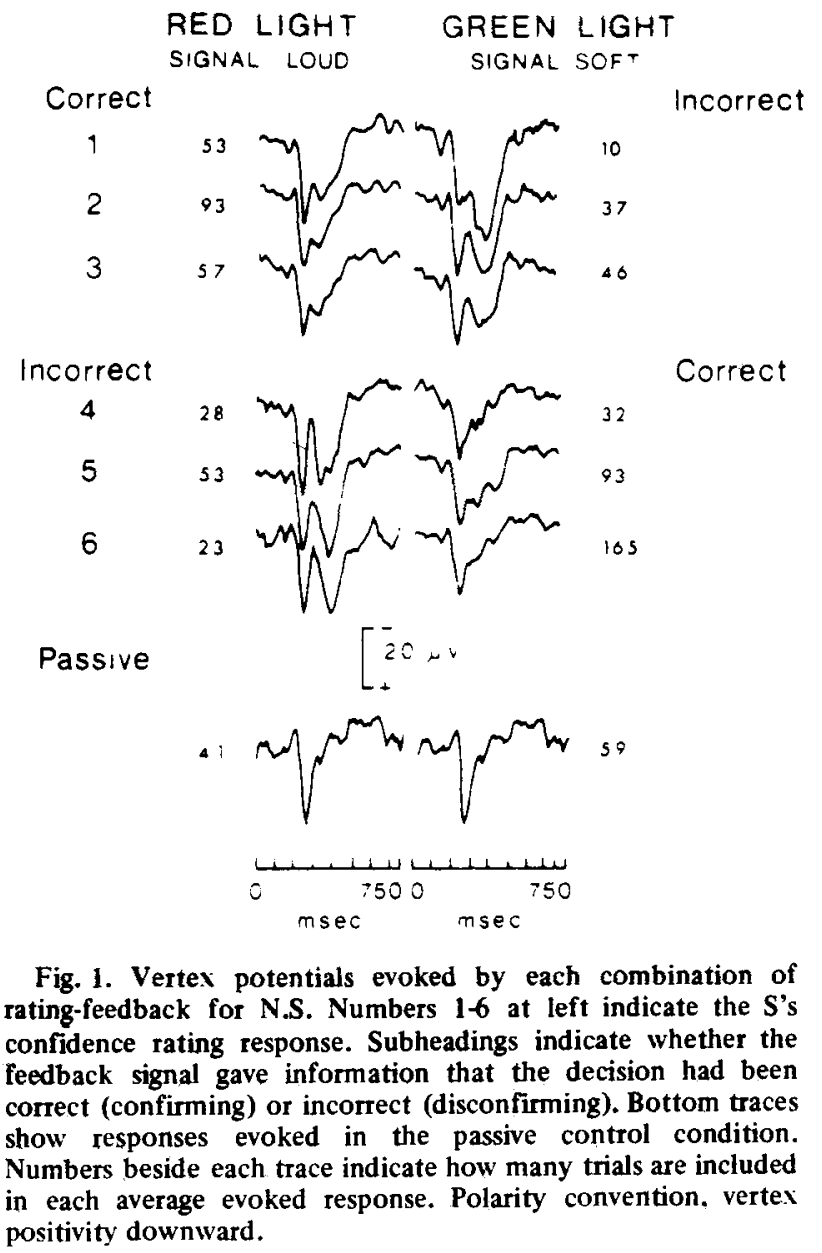
RED LIGHT
(SIGNAL LOUD)
GREEN LIGHT
(SIGNAL SOFT)

Correct
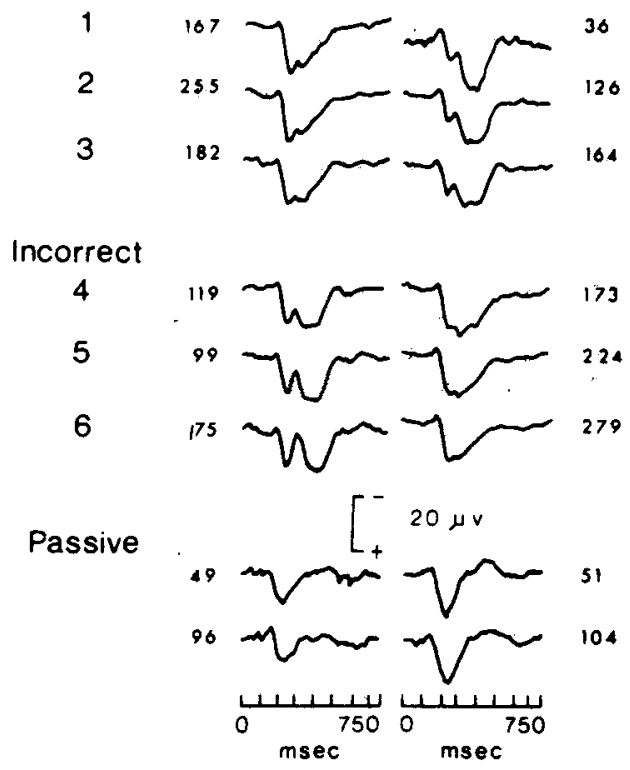

Correct

Fig. 2. Same as Fig. 1 for K.S.

occur. Because of prior reports that P3 amplitude is largely determined by signal probabilities (Sutton et al, 1965; Tueting et al, 1971), this relationship requires further examination.

Table 3 presents the linear correlations averaged over all Ss between P3 area and both the joint and contingent probability of receiving a given feedback signal. There is a strong overall inverse relation between P3 area and both of the probability measures; however, this inverse relation is not strong for the within-category data, particularly within the disconfirming group. In fact, while all eight Ss had strong overall negative correlations between $\mathrm{P} 3$ area and both probability measures (r ranged from -0.50 to -0.78 with joint probability and from -0.61 to -0.94 with contingent probability), two Ss (R.E. and J.G.) had positive correlations within the disconfirming group with both measures. Three other Ss (E.K.. J.S.. and N.H.) had positive correlations with either joint or contingent probability within the disconfirming group. while still having a substantial overall negative correlation between $\mathrm{P} 3$ area and that probability measure. Thus, there are a number of instances where changes in probability of occurrence are not matched by corresponding changes in $\mathrm{P} 3$ area. Much of the overall correlation must therefore be due to the dichotomy in the size of P3 across the boundary between confirming and disconfirming feedback.

The latency to the peak of the P 3 component $w$ as also found to increase with an increasing discrepancy between the feedback and the decision, but the size of the effect varied between Ss. For three Ss (K.S.. E.K.. 
Table 2

Area of P3 in Interval Between 300-450 Postsignal Onset Relative to a Baseline of the First $60 \mathrm{Msec}$ of the Feedback Interval as a Function of the Degree to Which the Feedback Contirms the Decision*

\begin{tabular}{|c|c|c|c|c|c|c|c|}
\hline \multirow{2}{*}{$\frac{S}{\text { is }}$} & \multicolumn{2}{|c|}{$\begin{array}{c}\text { Discontirm } \\
\text { High }\end{array}$} & \multicolumn{2}{|c|}{ Low } & \multicolumn{2}{|c|}{$\begin{array}{c}\text { Confïm } \\
\text { High }\end{array}$} & \multirow{2}{*}{$\frac{\text { Control }}{125}$} \\
\hline & 1221 & 992 & 908 & 570 & 602 & 500 & \\
\hline JS & 1101 & 1165 & 908 & 569 & 344 & 329 & 50 \\
\hline $\mathrm{NH}$ & 777 & 835 & $8 \geq 0$ & 360 & 372 & 187 & 18 \\
\hline $\mathrm{KS}$ & 822 & 877 & 820 & 770 & 667 & 565 & -88 \\
\hline $\mathrm{EK}$ & 675 & 555 & 725 & 537 & 474 & 377 & 75 \\
\hline SH & 852 & 785 & 703 & 645 & 438 & 370 & 119 \\
\hline RE & 360 & 420 & 463 & 335 & 276 & 172 & -156 \\
\hline JG & 735 & 965 & 827 & 687 & 524 & 438 & 3 \\
\hline
\end{tabular}

*Reading from left to right gires areas for increasingly close agreement between the iudgment and feedback. Last columm is the P3 area in the control condition. Area measite is expressed in $\mu \mathrm{rolt} \cdot \mathrm{msec}$

and N.S.). there was a large increment $(95,80$. and 70 msec. respectively) of $\mathrm{P} 3$ latencies following the most highly disconfirming feedback in relation to the most confirming feedback: for two Ss, the increment was less (J.S.. $30 \mathrm{msec}$ S.H.. $15 \mathrm{msec}$ ): and for the other three Ss. the effect was negligible (less than $5 \mathrm{msec}$ ). The mean P3 latency difference between disconfirming and confiming feedback was $25 \mathrm{msec}(\mathrm{p}<.01)$. For no $\mathrm{S}$ was the average latency of P3 evoked by confirming feedback shorter than the average latency of P3 following disconfirming feedback.

\section{DISCUSSION}

In their initial report. Sutton et al (1965) noted that feedback signals which proved prior guesses to be incorrect elicited larger P3 waves than did confirming feedback. Subsequent studies using this two-choice guessing paradigm, however, showed that P3 amplitude varied inversely with the joint probability of occurrence of a guess-feedback outcome (Tueting et al, 1971). The P3s following disconfirming feedback were larger only because those signals were less frequent than confirming feedback. It was accordingly suggested that

Table 3

Linear (Product-Moment) Correlation Coefficients Between the P3 Area and Probabilities of Occurrence (Joint and Contingent) of Each Type of Trial*

\begin{tabular}{lccc}
\hline & $\begin{array}{c}\text { Orerall } \\
(\mathrm{df}=94)\end{array}$ & $\begin{array}{c}\text { Confirming } \\
(\mathrm{df}=46)\end{array}$ & $\begin{array}{c}\text { Discon- } \\
\text { firming } \\
(\mathrm{df}=46)\end{array}$ \\
\hline $\begin{array}{l}\text { Joint } \\
\text { Probability }\end{array}$ & -0.61 & -0.34 & -0.12 \\
$\begin{array}{l}\text { Contingent } \\
\text { Probability }\end{array}$ & -0.72 & -0.52 & 0.06 \\
\hline
\end{tabular}

* Area measures for each $S$ expressed as the proportion of the largest area lalue for euch $S$. tierage of eight $S$ s. "unexpectedness" might be a primary psychological correlate of P3.

The growth of $\mathrm{P} 3$ magnitude observed in the present experiment as a function of the discrepancy between the perceptual judgment and feedback is largely in accord with the results and interpretation of Tueting et al. An observer performing at above-chance level will receive disconfirming feedback less frequently than confirming feedback. These rating scale judgments are, therefore, analagous to the "low risk" guesses of Tueting et al, who similarly reported that disconfirmation of low risk guesses produced larger P3s than did confirming feedback. but as a function of outcome probability. However. we observed both a partial dichotomy of P3 magnitude between confirming and disconfirming feedback and a uniformity of P3s within the latter category, neither of which was solely due to variations in outcome probability. This suggests that P3 may reflect events that are more highly differentiated between right and wrong in the discrimination paradigm than in the guessing game of Tueting et al.

A fundamental distinction between the guessing and

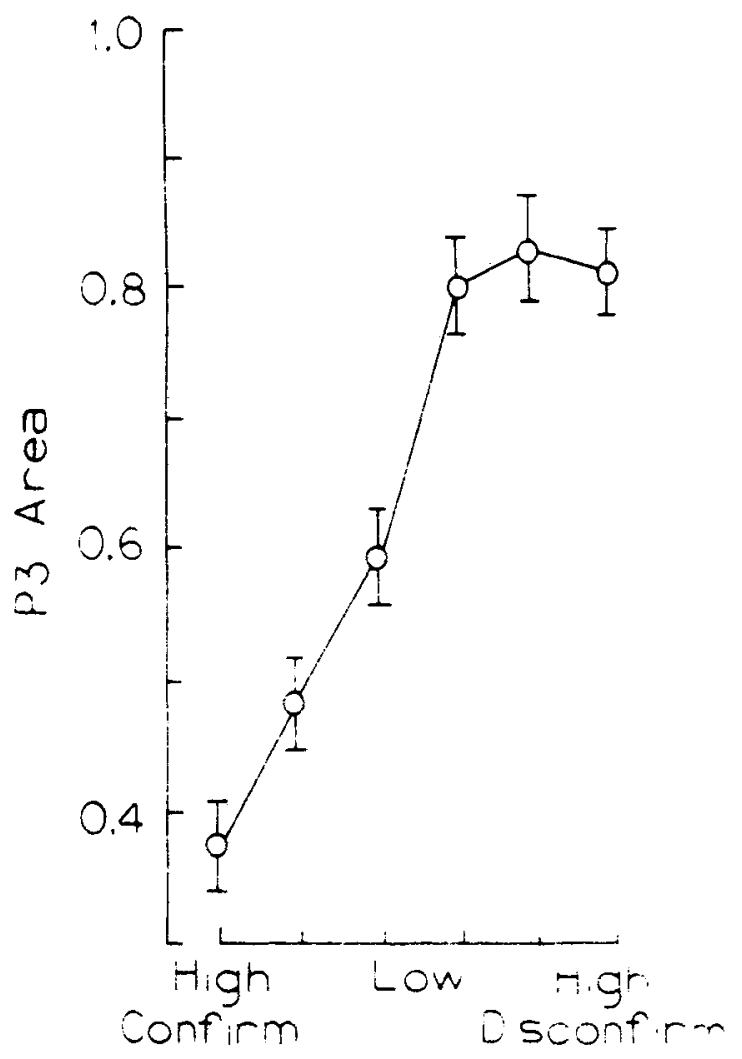

Fig. 3. Area of P3 between 300 and $450 \mathrm{msec}$ post signal onset relative to a baseline of the first $60 \mathrm{msec}$ of the feedback interval. Areas for each $S$ were first converted to proportions of the maximum value for each $S$. Plotted as a function of the degree to which the feedback confirmed or disconfirmed the decision. Average of eight Ss. Brackets indicate \pm 1 standard error. 
discrimination paradigms is that expectations of feedback in the latter are based upon sensory data rather than upon pure chance. Therefore, there is likely to be a stronger commitment to the decision, such that its disconfirmation has greater import than the contradiction of an "unbiased" guess. Moreover, since feedback information can be used to refine discriminations made on subsequent trials, postfeedback processing is more complex and likely to be more distinctive between correct and incorrect than it is in the guessing game.

In a previous report (Hillyard et al, 1971), P3 amplitude was related to the S's confidence in his correct detection of a near-threshold signal. Attending to a specific stimulus was conceived of as matching sensory input against the features of a stored "neuronal model" (Sokolov, 1963) or "template" of the stimulus. When the sensory signal matches the template, a "detect" decision is made with some level of confidence and a concomitant P3 determined by the closeness of the match. In the feedback paradigm, however, the distinction between the red and green lights is obvious and can be made with complete confidence, so additional factors must underlie the differences in P3. The behavior of P3 in this task and those cited previously seems compatible with the model of perceptual decision making outlined below, which specifies that $\mathrm{P} 3$ varies directly with the closeness of the template match and inversely with the degree of expectancy (subjective likelihood or certainty) (Sutton et al, 1965) of that signal.

The basic structure of tasks in which P3s are evoked consists of a "task-relevant" signal, which, when recognized, is coupled with a motor response or cognitive operation. In other words, these are tasks involving specific stimulus-response "sets." Our model assumes that a template-matching decision mechanism is established to register the occurrence of each expected, task-relevant signal, in the manner of Sokolov's "model" or Treisman's (1969) target "analyzer." It is proposed that this signal detector operates in two stages. In the first, "template-matching," stage, stimulus input is analyzed with reference to the particular template specifications, and an output proportional to the closeness of the match is led to the second. "decision." stage. Here, the output from the template stage is added to a "bias" level that is set in advance according to the S's expectancy that the signal will occur. If the sum of the template output and the expectant bias level exceeds a "critical level" of the decision stage.' an affirmative decision is made. The final property of the decision stage is a "ceiling" (which may vary according to the task) on the level which can be attained by the sum of the template output and the expectant bias level. The amplitude of $P_{3}$ then corresponds to the size of the stimulus-locked shift from the presignal bias level upon receipt of the output from the template-matching stage. Accordingly. this increment is proportional to the "goodness" of the template match but inversely related to the prior expectancy, since the effect of raising the bias' level is to limit the maximum extent of the positive shift.

The difference between P3s evoked by confirming vs disconfirming feedback may be explained on the basis of differential expectancies. Following a very confident discrimination (a rating of 1 or 6 ), the $S$ has high expectations of receiving confirming feedback. As a result, the bias level is elevated, such that only a small increment is possible before reaching the ceiling level, thereby reducing the size of $\mathrm{P} 3$. On the other hand. the disconfirming feedback can elicit a large increment because of the lower expectancy of that signal. An explanation for the partial dichotomization of P3 amplitudes between confirming and disconfirming feedback (Fig. 3) might be that the Ss adopt a more uniformly low expectancy of being incorrect than the objective probabilities would dictate.

The shorter latencies of the $\mathrm{P} 3 \mathrm{~s}$ evoked by confirming feedback in some Ss may also be attributed to the greater expectant bias upon the decision stage, since for a highly expected signal less stimulus information need be analyzed (via the template match) before reaching an affirmative decision, in accordance with well-established principles of perception (Bruner, 1957). Alternatively. the latency effect might be due to a serial comparison of the signal against a "list" of templates, proceeding from the most to the least expected.

In the threshold-level detection task (Hillyard et al, 1971), there is little trial-to-trial variation in expectancy when the signal remains fixed. The evocation of P3s on correct detection trials (HITS) but not on MISS trials (Hillyard et al, 1971: Paul \& Sutton, 1972; Squires et al ${ }^{1}$ ) can be attributed to spontaneous variation in the closeness of the template match. At very low signal levels, the expectancy of hearing a signal on each trial is low, creating ample latitude for large P3s. yet the observed P3 for HITS is small, presumably because the template matches are not close. On the other hand. when the signals are intense enough to be easily and confidently detected. the increased expectancy of hearing the signal raises the bias level so that the $\mathrm{P} 3$ on HITS cannot rise to the maximum amplitude achieved at the intermediate signal levels.

The P3 amplitude for a HIT in the detection task increases as the S's criterion for deciding that a signal has occurred becomes more strict (Hillyard et al. 1971: Paul \& Sutton. 1972: Squires et $\mathrm{al}^{1}$ ). In our model. the critical level of the decision stage is analogous to the signal detection concept of decision criterion, and the input to the decision stage is analogous to the "sensory magnitude," which determines a "yes" decision when it exceeds the criterion level and a "no" when below (Green \& Swets. 1966). The amplitude of P3 on HITS increases with the strictness of the criterion because a larger output from the template-matching stage is required to surpass the critical decision level. When 
criterion is raised by reducing the a priori signal probability (Paul \& Sutton. 1972). however. P3 might be further enhanced as a result of the lower bias level on the decision stage.

To account for the enlarged P3 following an "unexpected" omission or change in a repetitive signal (Klinke et al. 1968: Ritter \& Vaughan, 1969). it need only be assumed that a template becomes established to register the occurrence of the rare event. This assumption is borne out by the huge increase in the P3 evoked by missing clicks in a series when the $S$ attends to these events (e.g. by counting them) in comparison to when the clicks are ignored (Barlow, 1969: Picton, et al, 1972).

Karlin and Martz (1972) have presented evidence to suggest that $\mathbf{P} 3$ amplitude is inversely related to the probability of the specific stimulus-response pair or set rather than the stimulus probability per se. If this is correct. our model is easily modified to state that the subjective probability or expectancy of a signal and the consequent bias on its decision stage is a function of the likelihood of the entire stimulus-response set. For any given task. then, there would be a hierarchy of stimulus-response sets, some more expected than others. Accordingly. the finding that the P3 evoked by a "no-go" signal in a discrimination reaction time task is larger than for the "go" signal (e.g.. Karlin et al, 1971), can be explained by assuming that Ss expect (and are "set for") the "go" signal response more than for the "no-go" signal (despite their objective 50-50 probabilities.

During the period of expectancy preceding feedback. a slow negative potential shift (CNV) reportedly develops (Picton \& Low, 1971). Since CNVs were not recorded in the present study, it is conceivable that different types of CNVs follow different-level confidence ratings and interact with the P3. However, since both the largest and smallest P3s were elicited by feedback following the highest confidence decisions, it is clear that prior CNVs could not be the sole determinant of the feedback effect. While several studies have found considerable independence between $\mathrm{CNV}$ and $\mathrm{P} 3$ amplitudes (Donald \& Goff. 1971: Sutton. 1970: Hillyard et al, 1971), it is yet conceivable that CNVs might participate subtly in the mechanism by which expectancy affects the $\mathrm{P} 3$ component.

\section{REFERENCES}

Barlow. J. Some observations on the electrophysiology of timing in the nervous system. Electroencephalography \& Clinical Neurophysiology, 1969, 27, 545: (A).

Benson, D., \& Teas, D. Human auditory-evoked response: Specific effects of signal strength and performance criterion. Perception \& Psychophysics. 1972, 11, 203-208.

Bruner. J. S. On perceptual readiness. Psychological Review, 1957. 64, 123-152.

Donald. M.. Jr.. \& Goff, W. Attention-related increases in cortical responsivity dissociated from the contingent negative variation. Science. 1971, 172.1163-1166.
Donchin. E.. \& Smith, D. B. D. The contingent negative variation and the late positive wave of the average evoked potential. Electroencephalography \& Clinical Neurophysiology. 1970. 29. 201-203.

Green. D. M.. \& Swets. J. A. Signal detection theory and ps.'choph!'sics. New York: Wiley. 1966.

Hillyard. S.. Squires. K.. Bauer. J., \& Lindsay. P. Lvoked potential correlates of auditory signal detection. Science. $1971,172.1357-1360$.

Hirsh. S. Vertex potentials associated with an auditory discrimination. Psychonomic Science, 1971. 22. 173-175.

Jenness. D. Auditory evoked response differentiation with discrimination learning in humans. Doctoral dissertation. Columbia University, 1970.

Karlin. L. Cognition. preparation, and sensory-evoked potentials. Psychological Bulletin, 1970. 73, 122-136.

Kariin. L., \& Martz, M. Response probability and sensory evoked potentials. In S. Kornblum (Ed.). Attention and performance IV. New York: Academic Press, 1972.

Karlin. L.. Martz. M.. Brauth, S., \& Mordkoff. A. Auditory evoked potentials, motor potentials, and reaction time. Electroencephalography \& Clinical Neurophysiology. 1971. 31, 129-136.

Klinke. R., Fruhstorfer. H., \& Finkenzeller, P. Evoked responses as a function of external stored information. Electroencephalography \& Clinical Neurophysiology. 1968. 25. 119-122.

Nielson. D., Teas, D., \& Idzikowski, R. Variation in cortical evoked responses as a function of performance criterion. Perception \& Psychophysics. 1970. 8. 29-32.

Paul, D., \& Sutton, S. Evoked potential correlates of response criterion in auditory signal detection. Science, 1972, 177. 362-364.

Picton. T., \& Low, M. The CNV and scmantic content of stimuli in the experimental paradiom: Effects of feedback. Electroencephalography \& Clinical Neurophysiology. 1971. 31. $451-456$.

Picton, T.. Hillyard, S., \& Galambos. R. Evoked responses to omitted stimuli. In M. N. Livanov (Ed.). Najor problems of brain electrophysiology. Moscow: USSR Academy of Science. in press.

Ritter, W. \& Vaughan. H.. Jr. Average evoked responses in vigilance and discrimination: A reassessment. Science. 1969. 164. 326-328.

Ritter. W.. Vaughan. H.. Jr.. \& Costa. L. Orienting and habituation to auditory stimuli: A study of short term changes in average evoked responses. Electroencephalography \& Clinical Neurophysiology. 1968, 25, 550-556.

Sheatz, G.. \& Chapman. R. Task relevance and auditory evoked responses. Electroencephalography \& Clinical Neurophysiology. 1969. 26. 468-475.

Shelbourne. S. Visual evoked responses to word and nonsense syllable stimuli. Electroencephalography \& Clinical Neurophysiology, 1972. 32.17-26.

Smith, D. B. D., Donchin, E., Cohen, L.. \& Starr. A. Auditory average evoked potentials in man during binaural listening. Electroencephalography \& Clinical Neurophysiology. 1970. 28, 146-152.

Sokolov. Y. N. Perception and the conditioned reflex. New York: Pergamon Press. 1963.

Sutton. S. The sensitivity of the evoked potential to psychological variables. Electroencephalography \& Clinical Neurophysiology, 1971. 31, 302 (A).

Sutton, S.. Braren. M.. Zubin. J.. \& John. F. R. Evoked-potential correlates of signal uncertainty. Science. 1965, 150. 1187-1188.

Sutton, S.. Tueting. P.. Zubin. J., \& John. E. R. Information delivery and the sensory cvoked potential. Science. 1967.155. 1436-1439.

Treisman. A. Strategies and models of selective attention. Psýchological Review. 1969. 76. 282-299. 
Tueting. P., Sutton, S., \& Zubin, J. Quantitative evoked potential correlates of the probability of events, Psychophysiology, 1971, 7, 385-394.

Wilkinson, R., \& Morlock, H. Auditory evoked response and reaction time. Electroencephalography \& Clínical Neurophysiology. 1967, 23, 50-56.

\section{NOTE}

1. Squires, K., Hillyard, S., \& Lindsay, P. Vertex potentials evoked during auditory signal detection: Relation to decision criteria. In preparation.

(Received August 14, 1972;

revision received October 3,1972 .) 